\title{
Selection, Gene Interaction, and Flexible Gene Networks
}

\author{
R.J. GREENSPAN \\ The Neurosciences Institute, San Diego, California 92121 and The Kavli Institute for Brain and Mind, \\ University of California at San Diego, La Jolla, California 92093-0526 \\ Correspondence: greenspan@nsi.edu
}

\begin{abstract}
Recent results from a variety of different kinds of experiments, mainly using behavior as an assay, and ranging from laboratory selection experiments to gene interaction studies, show that a much wider range of genes can affect phenotype than those identified as "core genes" in classical mutant screens. Moreover, very pleiotropic genes can produce specific phenotypes when mild variants are combined. These studies also show that gene networks readily change configuration and the relationships between interacting genes in response to the introduction of additional genetic variants, suggesting that the networks range widely and have a high degree of flexibility and malleability. Such flexibility, in turn, offers a plausible mechanism for the molding of phenotypes through microevolution, as a prerequisite to making a suitable environment for the acceptance of newly arising large-effect mutations in the transition from microevolution to macroevolution.
\end{abstract}

The concept of single-gene mutant analysis to study the mechanisms of behavior is now so deeply embedded as an analytical approach that its history of being challenged seems unimaginable. This is the legacy of Seymour Benzer's foray into the behavior of the fruit fly 40 years ago. But challenged it was, and from very divergent sources, including traditional neurobiologists (see, e.g., Hoyle 1974; Purves and Lichtman 1985) and a former molecular biologist (Stent 1982). A third challenge came from quantitative behavior genetics and pitted the two founders of Drosophila behavior genetics, Jerry Hirsch and Seymour Benzer, against each other over the issue of natural versus induced variants. In the late 1960s, when Benzer began his program of inducing mutants affecting behavior, Hirsch had already been performing selection experiments to produce heritable behavioral differences in fruit flies for nearly 10 years (Greenspan 2008). Hirsch's objection was that the induced mutants coming out of Benzer's screens were unnatural, would never survive in the wild, and therefore gave a misleading picture. From Benzer's point of view, the inability to identify, let alone analyze, the genes underlying Hirsch's selected phenotypes rendered that whole program useless.

In one sense, the conflict was moot because each side had a different goal. Hirsch's goal was to understand genetic architecture and the sources of natural phenotypic variation, and Benzer's was to understand mechanism in what has become the dominant molecular paradigm of explaining biological processes in terms of core genetic mechanisms that function in pathway-like fashion (Greenspan 2001). But the issue of reconciling natural variation affecting a phenotype with induced mutants has surfaced again as the advancing molecular armamentarium has made possible the identification and analysis of both kinds of variants. Recent studies on the molecular basis of selected phenotypes raise some puzzling questions about the relationship between natural and induced variants. A separate set of studies on gene interaction shows that a much wider range of genes can (and do) affect phenotype than those normally considered to be core genes. Such findings have some interesting implications for the molding of phenotypes through microevolution, as well as for ways of thinking about the transition from microevolution to macroevolution. They may also require us to modify our picture of how molecular pathways affect phenotypes.

\section{DISCREPANT GENES}

Following in Hirsch's footsteps, selection has been conducted on a variety of Drosophila behaviors since his inaugural work in the late 1950s (for review, see Greenspan 2004a). With the advent of microarray technology, several recent selection experiments have been subjected to gene expression profiling as a way of characterizing molecular differences between selected and unselected (or divergently selected) phenotypes.

The genes so identified are mixed with respect to their direct relationship to the selected phenotype. Some of the expression differences may actually be in the relevant polymorphisms, others surely are not. Expression level differences have been previously shown to underlie many mutant effects on behavior (Greenspan 1997) including natural variants (Osborne et al. 1997). In cases where the expression differences are not in the actual polymorphic genes, some may nonetheless be the consequences of such differences, e.g., downstream targets of transcription factors, and may thus take us one step closer to the actual basis for the phenotypic effect. A gene's role can sometimes be confirmed if it is capable of exerting an isolated effect on the phenotype, as shown in tests of independently isolated mutants (see below). Of course, there will be cases where the expression differences are phenotypically irrelevant and simply reflect hitchhiking variants that are linked to the selected loci. And finally, there will certainly be relevant allelic differences that are missed by 
this technology due to the fact that they are not caused by expression level differences or that they are so spatially restricted that their magnitude would not stand out against the background of activity elsewhere. Despite all of these caveats, expression profiles provide a rough sketch of the differences underlying selection effects.

Most laboratory selection experiments with Drosophila are short term and performed on small populations, on the order of 20-30 generations selecting the top $\sim 10 \%$ of a population of $\sim 200$ (Greenspan 2004a). Expression profiles have been done on RNA extracted from fly heads (mostly brain) of $D$. melanogaster strains differentially selected for mating speed (Mackay et al. 2005), aggression (Fig. 1) (see Dierick and Greenspan 2006; Edwards et al. 2006), and locomotor activity (Jordan et al. 2007). All have yielded a bewilderingly wide range of genes, as is common with microarray results. Two notable attributes are shared by all of these studies. First, the expression differences found for those genes significantly differing between strains are relatively small, almost all less than twofold in magnitude. One might attribute this feature to the likelihood that most natural variants are relatively mild. The second feature is the lack of any overlap between these genes and any that had previously been identified through classical, Benzerian mutant analysis (Hall 1982, 1994a; Kyriacou and Hall 1994; Wilson et al. 2008). This is all the more surprising given the number and range of genes that differ in these experiments. The question of how well expression analysis identifies the pertinent genes is addressed below.

Few selection experiments, behavioral or otherwise, go on for more than 30 generations, and very few of these have been analyzed molecularly. One of the rarities is a medium-term selection experiment for divergence in wing morphology that was conducted during a time frame more than twice as long as usual. An initial 20 generations of selection produced divergence in wing shape as measured by the ratio of a transect in the distal wing to a transect in the proximal wing (Fig. 2, left) (see Weber 1990). At generation 21 (Fig. 2, right), the two divergent lines were mixed and allowed to interbreed for 34 generations, at which time they were reselected for the same wing parameter divergence-four replicates in each direction-for another 25 generations (Weber et al. 2008).
Expression profiles were done on wing disc tissue dissected from these strains. The magnitude of the differences was somewhat higher than in the shorter-term selection experiments, with many more of them exceeding twofold (Weber et al. 2008). Much more striking, however, is the continued lack of overlap between these differentially expressed genes and any of the more than 200 genes identified over the years as affecting wing development (Brody 1999). Any concern from the earlier analyses that the phenotypes may have been undersampled in the mutagenesis studies is adequately allayed here.

The final example of a selection experiment subjected to expression analysis is perhaps the record holder for long-term laboratory selection in a metazoan. The indoor record for selection in any organism is 10,000 generations for Escherichia coli (Lenski and Travisano 1994), but in 1958, Jerry Hirsch began selecting Drosophila for divergence in geotaxis behavior and continued doing so for more than 600 generations until the lines stabilized spontaneously in 1983 (Fig. 3, left) (see Hirsch 1959; Ricker and Hirsch 1985). When tested again in 2000, they still displayed the appropriate phenotypic difference (Fig. 3, right) (see Toma et al. 2002).

Gene expression profiles were obtained for RNA from heads of the divergent strains, and, as usual, many genes differed. The magnitude of expression difference in these flies was considerably greater than that in any of the previous examples, with many showing fourfold to eightfold differences and a few even higher (Toma et al. 2002). And as in the earlier examples, the differing genes showed no overlap with any of the genes identified previously as geotaxis mutants (Armstrong et al. 2006).

Two trends stand out from this admittedly small set of examples. First, none of the genes match those found in standard mutant searches, and second, the magnitude of the genetic variation between strains, as measured by expression differences, increases with longer selection regimes.

The discrepancy between the two sets of genes may have several possible explanations. Many of the expression differences that diverge in these strains will be irrelevant to the divergent phenotypes. Some will be due to hitchhiking of variants that happen to be linked to those that are relevant, and others will be due to alterations in branches of
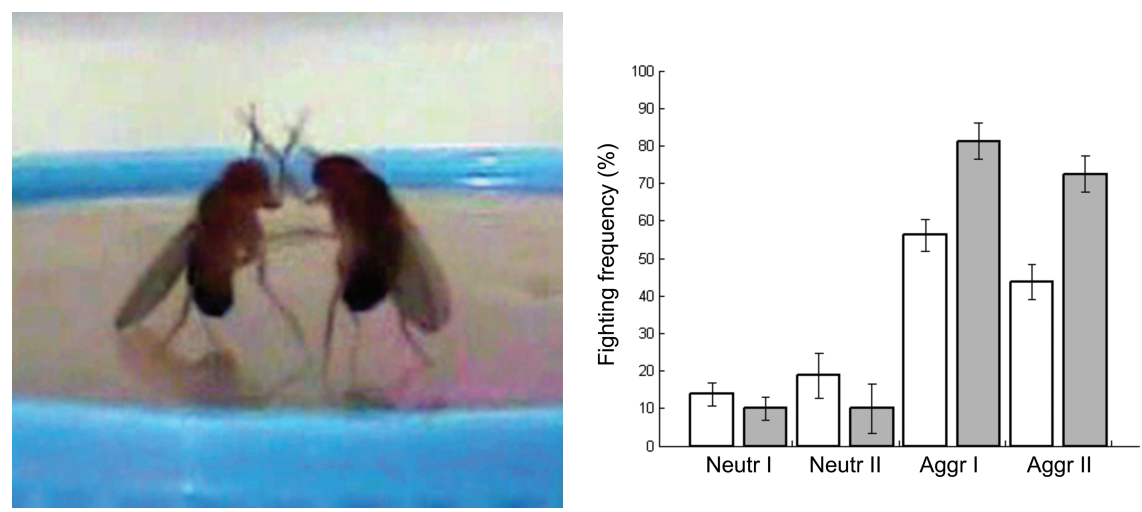

Figure 1. (Left) Fly aggression. (Right) Increased aggression with 20 generations of selection. (Right panel, Reprinted, with permission, from Dierick and Greenspan 2006 [CNature Publishing Group].) 

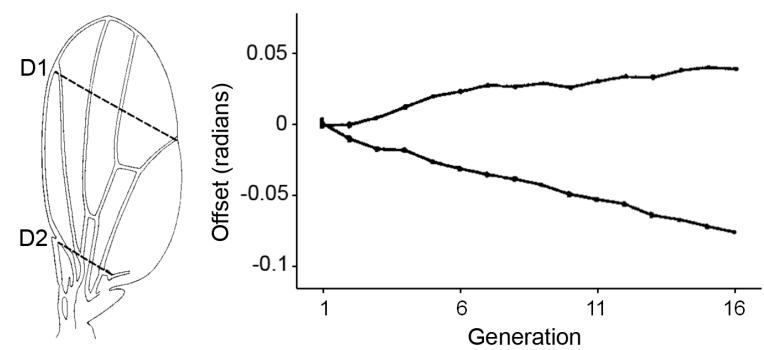

Figure 2. (Left) Wing parameters subjected to selection. (Right) Divergence during selection on wing parameters. (Reprinted, with permission, from Weber 1990 [CGenetics Society of America].)

transcriptional hierarchies that are not related to the selected phenotype. Genetic polymorphisms do not necessarily alter expression level; they can also alter timing, placement, or protein sequence. And even if they do, the effect could be so localized that it would not be detectable when averaging over a whole head or wing disc. On the other hand, it is well known that a great many mutations, including P-element mutations (see, e.g., Lerman et al. 2003) and natural variants (see, e.g., Osborne et al. 1997) in Drosophila, do actually alter levels of transcription.

The total lack of overlap is, however, rather striking, particularly in the case of wing morphology, where the tissue assayed was quite restricted (i.e., third instar larval wing discs), and the battery of genes known to affect wing development at that stage is extensive. Even if many of the expression differences are irrelevant, one might imagine that some of them would correspond to known mutants. One explanation is that there are many more ways of affecting a given phenotype beyond the "core" set of genes identified by standard mutagenesis.

\section{MORE THAN ONE WAY TO SKIN A CAT}

Support for the idea of a broad palette of available genes comes from several quarters. In a previous study of 50 randomly generated, homozygous viable P-element insertions, Weber et al. (2005) found 11 that affected the same wing morphology phenotype, and none overlapped with the known set of wing development genes. In a much broader screen of more than 2800 P-element insertions for alterations in bristle number, a similar proportion $(\sim 22 \%)$ was found to produce significant effects, and these covered a much wider range of genes than those previously identified in mutant screens (Norga et al. 2003). Another, much larger, screen for randomly generated homozygous viable P-element insertions yielded 263 that were then tested for activity levels of 14 metabolic enzymes (Clark et al. 1995). More than $50 \%$ of them (153) produced significant alterations in activity for at least one enzyme, and $15 \%-20 \%$ of them affected two or three enzymes. These are the so-called "housekeeping" enzymes that are not supposed to change. And finally, a recent search for P-element mutants affecting the startle response yielded 267 of 720 lines screened, including many with no obvious relationship to neural mechanisms (Yamamoto et al. 2008).

Coming to the same conclusion from a different origin, genome-wide screens for RNA interference (RNAi) effects have also revealed a much wider set of genes and mechanisms capable of significantly altering a phenotype than predicted from previous mutant studies, whether conducted in cell culture (Friedman and Perrimon 2007) or in the intact animal (Byrne et al. 2007). And from yet another direction, analysis of differences in natural variants between two different fly strains, and the effects on global gene expression of those strain differences, implicates a wide range of pleiotropic genes in many behaviors (Ayroles et al. 2009; Edwards et al. 2009; Harbison et al. 2009).

The second trend seen with increasing length of selection is the greater magnitude of gene expression differences. These could be either due to changes at the relevant loci themselves or the result of selection for gene interactions that affect expression. It has previously been suggested that new mutations could arise and spread after as few as 20 generations (Robertson 1980) and that combinations of interacting genes would increase over successive generations of selection (Wright 1963). The question of gene interactions resulting from selection bears further examination.

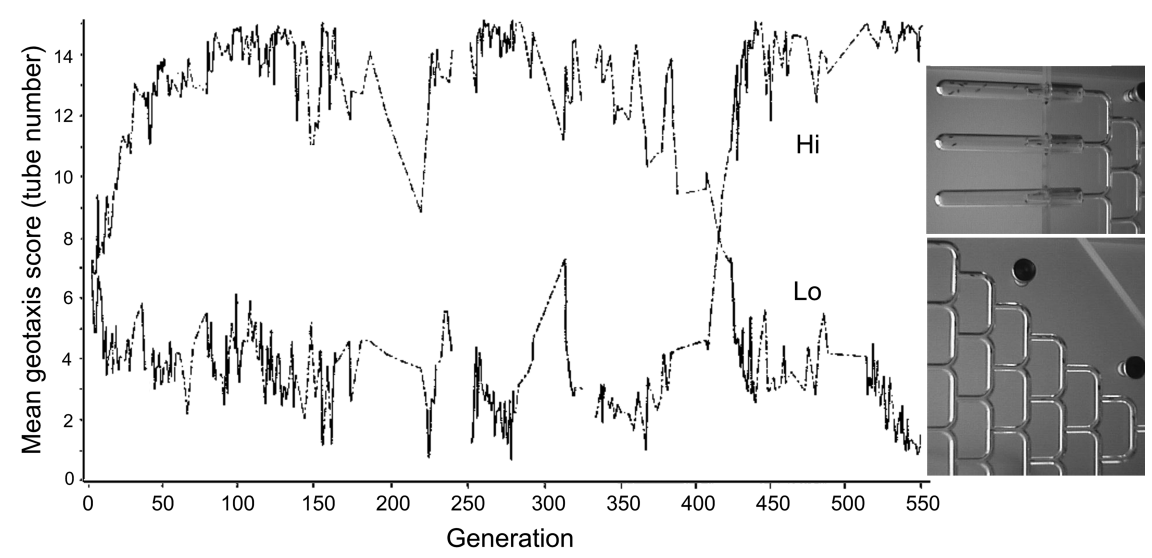

Figure 3. Long-term selection for geotaxis response producing "Hi" (negatively geotaxic) and "Lo" (positively geotaxic) strains. (Reprinted, with permission, from Ricker and Hirsch 1985 [CAPA].) Right upper panel: Topmost tubes of geotaxis apparatus showing "Hi" flies at the end of their run (courtesy of R.J. Greenspan). Right lower panel: Entry of "Hi" flies into the maze (courtesy of R.J. Greenspan). 


\section{WEAVING THE NETWORK OF GENE INTERACTIONS}

The importance of gene interactions in evolution has been a matter of controversy since the early days of population genetics (Fisher 1930; Wright 1931) and it goes on to this day (Coyne et al. 1997; Wade and Goodnight 1998; Desai et al. 2007). The original protagonists in this matter were R.A. Fisher and Sewall Wright. Their respective viewpoints are summed up in Figure 4, taken from one of Wright's last papers (Wright 1982), along with a third relevant viewpoint from J.B.S. Haldane. Fisher considered selected traits to be the result of the action of a large number of genes, each one of small effect and acting independently, summing to produce the final outcome. Wright also conceived of the process as multigenic, but rather than acting independently and summing, he saw the genes as interacting extensively in nonadditive (epistatic) ways. Haldane, in contrast, imagined single large-effect variants as responsible for phenotypic change. How do these formulations square with the findings from various selection experiments?

On the basis of statistical analyses of the phenotypes of $\mathrm{F}_{1}, \mathrm{~F}_{2}$, and backcross progeny, short-term selection seems to result mainly from additive interactions. For two of the selection experiments discussed here, additivity was found in the initial stages (generation 20) of Weber's wing morphology selection (Weber et al. 1999, 2001) and in the initial stages (generation 28) of Hirsch's geotaxis selection (Hirsch and Erlenmeyer-Kimling 1962). Further examples of short-term selection that found a similar lack of epistasis include knockdown resistance to ethanol (Cohan et al. 1989) and male mating speed (Caseres et al. 1993). Some short-term experiments did show epistasis as well as additivity: central excitatory state (Vargo and Hirsch 1986), female remating speed (Fukui and Gromko 1991), and locomotor activity (Mackay et al. 2005).

When selection goes on for longer times, it apparently produces greater epistasis, as illustrated in Hirsch's geotaxis experiment at generation 133 (McGuire 1992) and at generation 566 (Ricker and Hirsch 1988). A similar conclusion can be drawn by calculating interlocus epistasis in the data from a selection experiment for locomotion against a wind current performed by Weber (1996). Using the means of hybrids and parents as a measure, where 4F2 $-2 \mathrm{~F} 1-\mathrm{P} 1-\mathrm{P} 2 \neq 0$ if there is interlocus epistasis (Mather and Jinks 1977), significant epistasis begins to be detectable at generation 98 .

\section{LARGE-EFFECT MUTATIONS: ARTIFICAL OR NATURAL?}

The essence of single-gene mutant studies, and the principal criterion applied since Benzer inaugurated the strategy (Benzer 1967) and which has continued through the many screens for all kinds of phenotypes since then, is to isolate strong-effect mutations with little or no effect on other phenotypes. As regards the specificity of these mutations, this criterion is more honored in the breach than in the observance, as documented occasionally through the past few decades (Hall 1982, 1994b; Greenspan 2001). But by and large, the general idea holds, especially for the criterion of large effects.

Natural variants, in contrast, generally tend to be small in their effects (see, e.g., Hill and Caballero 1992; Mackay 2001), with rare exceptions (see below). This observation fits with the Fisher and Wright models for the polymorphisms that are acted upon by selection (Fig. 4, left and middle). As for the Haldane model (Fig. 4, right), is there any evidence for it? The notable exceptions to the smalleffect rule are single-gene polymorphisms that have been shown to account for most of the variance affecting central excitatory state in the blowfly Phormia (Tully and Hirsch 1982), larval foraging behavior in D. melanogaster (Sokolowski 1980), and aggregation behavior in Caenorhabditis elegans (de Bono and Bargmann 1998).

Among the selection experiments discussed above, Hirsch's long-term geotaxis selection exhibits two features that have more of a Haldanish quality: larger expression differences (Toma et al. 2002) and an ability of induced mutations in a single one of the differing genes, the neuropeptide $P d f$ pigment-dispersing factor (Renn et al. 1999), to recapitulate the strength and range of the selected phenotype when driven toward either nullness or overexpression (Toma et al. 2002). This degree of recapitulation is unmatched in any of the other selection experiments for which such tests have been made (Dierick and Greenspan 2006; Edwards et al. 2006) and constitutes a "near miss" in finding a gene by selection that could also have been found by a classical screen for single-gene mutants. Further evidence for the potency of this gene subsequently came from isolation of mutants in the neuropeptide's receptor, which also exhibited a negative geotaxis response as strong as that of Hirsch's "Hi" line (Mertens et al. 2005). Although far from definitive, these observations nonetheless suggest that long-term selection may be more likely to accumulate, and perhaps be more permissive for, large-effect variants.

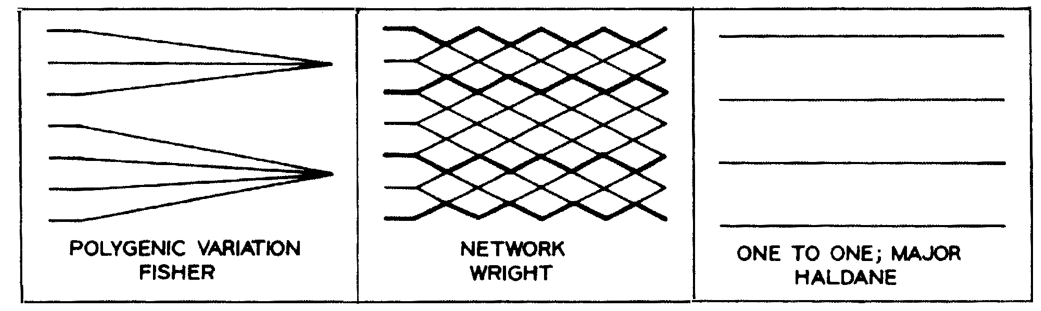

Figure 4. Three classic models of selection. (Reprinted, with permission, from Wright 1982 [CWiley-Blackwell].) 


\section{THE SEASONS OF SELECTION}

The foregoing discussion may offer a way of reconciling the differing points of view on modes of selection illustrated in Figure 4. As often happens in biological controversies, opposing viewpoints may simply represent valid pictures of what goes on at different times. Shortterm selection appears Fisherian with its multiple small, additive effect variants. Medium-term selection appears Wrightian with its multiple, increasingly epistatic interactions. And long-term selection appears Haldanish, with a strong Wrightian streak, in its larger-effect variants and more extensive epistatic interactions. Mechanistically, these stages are feasible from the standpoint of what is most likely to be available to work with initially, leading to a more extensive intertwining during a longer time period and eventually allowing for the appearance and fixation of new, larger-effect variants.

\section{THE DISCREPANCIES REMAIN}

The quandary remains, however, as to the apparent lack of concordance between selected variants and induced mutants. As summarized above, there is ample evidence that many more genes can affect phenotypes than are generally found in mutant screens, but what is the relationship between these two sets?

One interesting possibility, for which there is increasing evidence, is that the gene networks that subserve any phenotype are much wider ranging than previously suspected (Greenspan 2001, 2004b, and unpubl.). If it is the case that gene networks are wider ranging than we had thought, then it almost certainly must be due to extensive gene interactions. Can we also find evidence for this?

The most comprehensive approach of this sort has been global gene interaction studies in yeast (Tong et al. 2004; Roguev et al. 2008), demonstrating $\sim 4000$ interactions among 1000 genes, with interactions/gene ranging from 1 to $146(\mu=34)$. More extensive evidence for the breadth of gene action can be found in the literature on suppressor and enhancer screens. A representative example is the now classic studies done on the sevenless gene of Drosophila and its role in cell-fate determination in the retina. The standard protocol was to start with a moderate allele of the gene, with a rough eye phenotype that allowed for exacerbation by enhancers and amelioration by suppressors. Out of such screens, the sevenless pathway was assembled and its homology with mammalian oncogene tyrosine kinase/Ras/ MAP kinase signal transduction was clearly shown (Brennan and Moses 2000). If one looks more closely at the products of these suppressor/enhancer screens, one finds that a very wide range of interacting genes was identified (see, e.g., Simon et al. 1991), but not followed up, presumably due to the lack of clear involvement in the Ras pathway. These genes were, nonetheless, capable of modifying the sevenless phenotype and were thus sampling the wider space of relevant genes, now largely lost to the world.

\section{THE FLEXIBILITY OF GENE NETWORKS}

It has generally been assumed that the relationships among the elements of a pathway or network are stable. We have tested this assumption in an analysis of interactions among a set of genes affecting loss of coordination in Drosophila. Unlike most studies of gene networks, we defined a network in terms of functional interactions (rather than common phenotype), common biochemical function, or covariation of gene expression patterns. A classical analysis of epistasis was then performed on 16 mutations isolated on the basis of their interaction with a mutation of Syntaxin-1A (Syx1A), a component of the machinery of secretion and synaptic transmission (Richmond and Broadie 2002). We treated the temperature-sensitive induction of uncoordination in $\operatorname{Syx} 1 A^{3-69}$ mutants (Littleton et al. 1998) as a quantitative phenotype and tested their interactions based on statistical alteration of its time course of onset (Fig. 5, left).

Using epistatic (nonlinear) interactions between two genes as an indicator of a more intimate network relationship than additivity, we measured the relationships among all 16 suppressor/enhancer genes on an otherwise similar wild-type background (Fig. 5, middle). We then measured these interactions on the same background with the reintroduction of the original $S y x 1 A$ mutation, against which the suppressor/enhancers were isolated (Fig. 5, right). The resulting set of interactions defines a series of relationships among the genes.

The unexpected result is that the functional relationships among the 16 genes vary with genetic context: They

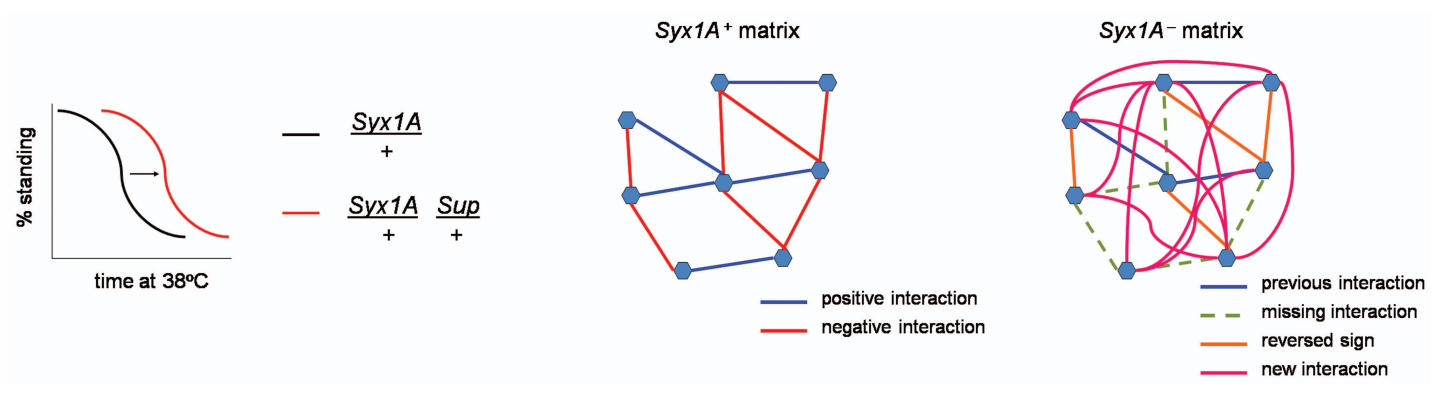

Figure 5. (Left) Test for epistasis among Syx-1A suppressors/enhancers. (Middle) Network of interactions among Syx-1A suppressor/enhancers in the absence Syx $1 A^{+}$and (right) presence of the original Syx-1A mutation used to identify them. (Modified, with permission, from Greenspan 2001 (CNature Publishing Group].) 
change dramatically depending on the presence or absence of the Syx $1 A$ mutation. This indicates a potential for network flexibility beyond that predicted by standard molecular biological models of gene interactions and implies that the network takes on different configurations under different conditions.

\section{FLEXIBILITY, ROBUSTNESS, AND DEGENERACY}

Flexible relationships among elements of a network are likely to be a major source of robustness as well as a source for the emergence of new properties. In contrast to the conventionally invoked mechanisms of local feedback or redundancy to account for such properties (Hartman et al. 2001; Davidson et al. 2002), the more far-flung interactions that we have uncovered may be better attributed to degeneracy, the wide-ranging ability of a system to produce the same output by different strategies. The finding that many different genotypes produce nearly identical behavioral scores exemplifies this property (cf. Hirsch 1963).

Degeneracy is a signature feature of biological systems in general (Edelman and Gally 2001) and of gene networks in particular (Greenspan 2001). Degenerate biological systems have many nonidentical elements (e.g., genes) that are extensively interconnected but that have nonuniform patterns of connectivity. The effective range of each gene is further enhanced by pleiotropy (see discussion above and Wright 1968). These properties endow biological systems with the ability to compensate for perturbations that may never have been encountered before. An important consequence of this property is that there is a great deal more latent potential in gene networks than has previously been revealed either by classical quantitative genetics, where the identities of interacting genes were not known, or by classical mutant analysis, where the scope of interaction was relatively narrow.

\section{A SHIFTING GENETIC LANDSCAPE}

An implication of our findings and of these ideas for mechanistic studies of gene action then arises: If the functional state of a gene network is perturbed when one of its elements is changed, then caution must be exercised in extrapolating back to a "normal" system state from mutant data. Moreover, it casts a shadow over the very concept of a normal system state, in much the same way that population geneticists have long questioned the notion of a "normal" individual (Hirsch 1963; Lewontin 1974).

This property has its counterpart in the nervous system where the functional connections shift under different conditions of stimulation (Marder and Thirumalai 2002). Unlike the nervous system, gene networks lack a constant underlying physical anatomy of connections to map. Thus, interaction mapping studies could potentially go on forever without ever producing a coherent system-wide set of relationships. Each result would be valid in its own context but not necessarily in many others.

\section{IMPLICATIONS: A PATH FROM MICRO TO MACRO}

What are the implications of all of this for understanding the process of evolution? If we take into account (1) the broad palette of networked genes available to affect any phenotype, (2) the increase in both epistasis and magnitude of gene effects with prolonged selection, and (3) the flexibility of network configurations with the introduction of new genetic variants, then a mechanism for the transition from small-effect to large-effect genetic changes during evolution may be discerned (Fig. 6).

In the short-term, selection gathers together the smalleffect variants that are segregating in the population to achieve a particular phenotypic outcome. As more time passes under selection, more intricate combinations of variants are woven together to produce a more potent mixture based on epistatic interactions. These interactions, in turn, mold the network into a new shape, commensurate with the selected phenotype. With still longer times, more extensive intertwining and network sculpting occurs, creating a genetic environment more tolerant of a newly arising large-effect variant that reinforces the phenotype without causing disruptions so drastic that the whole system crashes. Should such a variant arise, not only would it reinforce the existing network configuration, but it would also be far easier to inherit than the web of many variants required for the phenotypic effect up to that point. In time, the many small-effect variants could then scatter, leaving the large-effect change to perpetuate the network configuration. During that period, finer honing
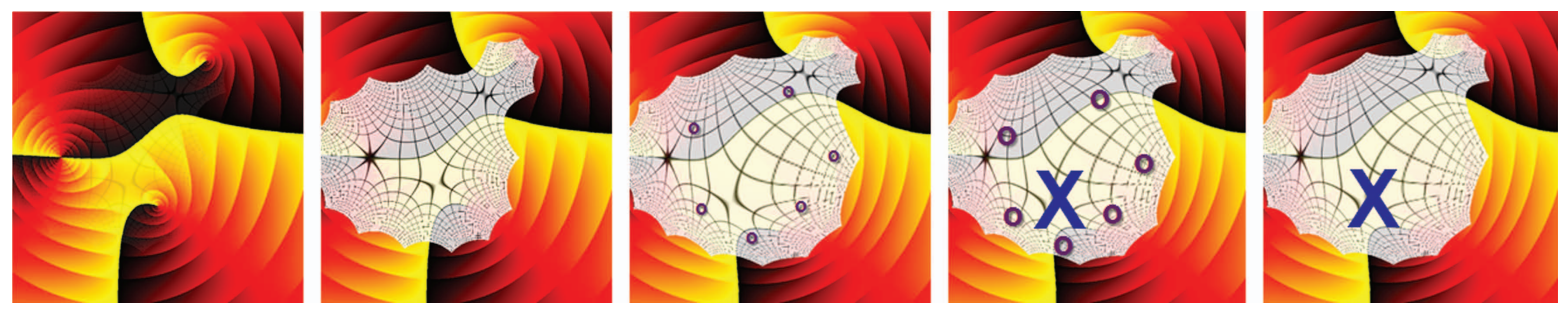

Figure 6. Stages in gene network alteration during selection for a new trait. (First panel) Topography of a phenotypic landscape. (Second panel) Wide-ranging gene network capable of affecting a given phenotype. (Third panel) Accumulation of multiple smalleffect variants and consequent distortion of the network relationships, creating an environnent capable of tolerating a large-effect variant (fourth panel) that reinforces the same network distortion. (Fifth panel) Subsequent loss of the small variants and persistence of the large variant. 
of the large variant, such as further nucleotide changes to a cis-acting sequence, could reduce deleterious effects or narrow the scope of the variant's effect.

A scenario of this sort could account for the relatively specific, relatively large-effect single-gene differences we find today as the remnants of species differences (see, e.g., Carroll et al. 1995). It could also provide a mechanism to account for the transition from microevolutionary to macro-evolutionary transformations.

\section{REFERENCES}

Armstrong JD, Texada MJ, Munjaal R, Baker DA, Beckingham KM. 2006. Gravitaxis in Drosophila melanogaster: A forward genetic screen. Genes Brain Behav 5: 222-239.

Ayroles JF, Carbone1 MA, Stone EA, Jordan KW, Lyman RF, Magwire MM, Rollmann SM, Duncan LH, Faye Lawrence F, Anholt RH, Mackay TFC. 2009. Systems genetics of complex traits in Drosophila melanogaster. Nat Genet 41: 299-307

Benzer S. 1967. Behavioral mutants of Drosophila isolated by countercurrent distribution. Proc Natl Acad Sci 58: 1112-1119.

Brennan CA, Moses K. 2000. Determination of Drosophila photoreceptors: Timing is everything. Cell Mol Life Sci 57: 195214.

Brody T. 1999. The interactive fly: Gene networks, development and the internet. Trends Genet 15: 333-334.

Byrne AB, Weirauch MT, Wong V, Koeva M, Dixon SJ, Stuart JM, Roy PJ. 2007. A global analysis of genetic interactions in Caenorhabditis elegans. J Biol 6: 8.

Carroll SD, Weatherbee SB, Langeland JA. 1995. Homeotic genes and the regulation and evolution of insect wing number. Nature 375: 58-61.

Casares P, Carracedo MC, San Miguel E, Piñeiro R, García-Flórez L. 1993. Male mating speed in Drosophila melanogaster: Differences in genetic architecture and in relative performance according to female genotype. Behav Genet 23: 349-358.

Clark AG, Wang L, Hulleberg T. 1995. P-element-induced variation in metabolic regulation in Drosophila. Genetics 139: 337 438.

Cohan FM, Hoffmann AA, Gayley TW. 1989. A test of the role of epistasis in divergence under uniform selection. Evolution 43: 766-774.

Coyne JA, Barton NH, Turelli M. 1997. Perspective: A critique of Sewall Wright's shifting balance theory of evolution. Evolution 51: 643-671

Davidson EH, Rast JP, Oliveri P, Ransick A, Calestani C, Yuh CH, Minokawa T, Amore G, Hinman V, Arenas-Mena C, et al. 2002. A genomic regulatory network for development. Science 295: $1669-1678$.

de Bono M, Bargmann CI. 1998. Natural variation in a neuropeptide $\mathrm{Y}$ receptor homolog modifies social behavior and food response in C. elegans. Cell 94: 679-689.

Desai MM, Weissman D, Feldman MW. 2007. Evolution can favor antagonistic epistasis. Genetics 177: 1001-1010.

Dierick HA, Greenspan RJ. 2006. Molecular analysis of flies selected for aggressive behavior. Nat Genet 38: 1023-1031.

Edelman GM, Gally JA. 2001. Degeneracy and complexity in biological systems. Proc Natl Acad Sci 98: 13763-13768.

Edwards AC, Rollmann SM, Morgan TJ, Mackay TF. 2006. Quantitative genomics of aggressive behavior in Drosophila melanogaster. PLoS Genet 2: e154.

Edwards AC, Ayroles JF, Stone EA, Carbone MA, Lyman RF, Mackay TF. 2009. A transcriptional network associated with natural variation in Drosophila aggressive behavior. Genome Biol 10: R76.

Fisher RA. 1930. The genetical theory of natural selection. Oxford University Press, New York.

Friedman A, Perrimon N. 2007. Genetic screening for signal transduction in the era of network biology. Cell 128: 225-231.

Fukui HH, Gromko MH. 1991. Genetic basis for remating in Drosophila melanogaster. IV. A chromosome substitution analysis. Behav Genet 21: 169-181.

Greenspan RJ. 1997. A kinder, gentler genetic analysis of behavior. Curr Opin Neurobiol 7: 805-811.

Greenspan RJ. 2001. The flexible genome. Nat Rev Genet 2: 383387.

Greenspan RJ. 2004a. The varieties of selectional experience in behavioral genetics. J Neurogenet 17: 241-270.

Greenspan RJ. 2004b. E pluribus unum, ex uno plura: Quantitativeand single-gene perspectives on the study of behavior. Annu Rev Neurosci 27: 79-105.

Greenspan RJ. 2008. The origins of behavioral genetics. Curr Biol 18: R192-R198.

Hall JC. 1982. Genetics of the nervous system in Drosophila. $Q$ Rev Biophys 15: 223-479.

Hall JC. 1994a. The mating of a fly. Science 264: 1702-1714.

Hall JC. 1994b. Pleiotropy of behavioral genes. In Flexibility and constraint in behavioral systems (ed. RJ Greenspan and CP Kyriacou), pp. 15-27. Dahlem Konferenzen Publications, Berlin

Harbison ST, Carbone MA, Ayroles JA, Stone EA, Lyman RF, Mackay TFC. 2009. Co-regulated transcriptional networks contribute to natural genetic variation in Drosophila sleep. Nat Genet 41: 371-375.

Hartman JL IV, Garvik B, Hartwell L. 2001. Principles for buffering of genetic variation. Science 291: 1001-1004.

Hill WB, Caballero A. 1992. Artificial selection experiments. Annu Rev Ecol Syst 23: 287-310.

Hirsch J. 1959. Studies in experimental behavior genetics. J Comp Physiol Psychol 52: 304-308.

Hirsch J. 1963. Behavior genetics and individuality understood. Science 142: 1436-1442.

Hirsch J, Erlenmeyer-Kimling LF. 1962. Studies in experimental behavior genetics. IV. Chromosome analyses for geotaxis. $J$ Comp Physiol Psychol 55: 732-739.

Hoyle G. 1974. Neural machinery underlying behavior in insects. In The neurosciences: Third study program (ed. FO Schmitt and FG Worden), pp. 397-410. MIT Press, Cambridge, MA.

Jordan KW, Carbone MA, Yamamoto A, Morgan TJ, Mackay TFC. 2007. Quantitative genomics of locomotor behavior in Drosophila melanogaster. Genome Biol 8: R172.

Kyriacou CP, Hall JC. 1994. Genetic and molecular analysis of Drosophila behavior. Adv Genet 31: 139-186.

Lenski RE, Travisano M. 1994. Dynamics of adaptation and diversification: A 10,000-generation experiment with bacterial populations. Proc Natl Acad Sci 91: 6808-6814.

Lerman DN, Michalak P, Helin AB, Bettencourt BR, Feder ME. 2003. Modification of heat-shock gene expression in Drosophila melanogaster populations via transposable elements. Mol Biol Evol 20: 135-144.

Lewontin RC. 1974. The genetic basis of evolutionary change. Columbia University Press, New York.

Littleton JT, Chapman ER, Kreber R, Garment MB, Carlson SD, Ganetzky B. 1998. Temperature-sensitive paralytic mutations demonstrate that synaptic exocytosis requires SNARE complex assembly and disassembly. Neuron 21: 401-413.

Mackay TF. 2001. Quantitative trait loci in Drosophila. Nat Rev Genet 2: 11-20.

Mackay TF, Heinsohn SL, Lyman RF, Moehring AJ, Morgan TJ, Rollmann SM. 2005. Genetics and genomics of Drosophila mating behavior. Proc Natl Acad Sci (suppl. 1) 102: 6622 6629.

Marder E, Thirumalai V. 2002. Cellular, synaptic and network effects of neuromodulation. Neural Netw 15: 479-493.

Mather K, Jinks JL. 1977. Introduction to biometrical genetics. Cornell University Press, Ithaca, NY.

McGuire TR. 1992. A biometrical genetic approach to chromosome analysis in Drosophila: Detection of epistatic interactions in geotaxis. Behav Genet 22: 453-467.

Mertens I, Vandingenen A, Johnson EC, Shafer OT, Li W, Trigg JS, De Loof A, Schoofs L, Taghert PH. 2005. PDF receptor signaling in Drosophila contributes to both circadian and geotactic behaviors. Neuron 48: 213-219.

Norga KK, Gurganus MC, Dilda CL, Yamamoto A, Lyman RF, Patel PH, Rubin GM, Hoskins RA, Mackay TF, Bellen HJ. 
2003. quantitative analysis of bristle number in Drosophila mutants identifies genes involved in neural development. Curr Biol 13: 1388-1396.

Osborne KA, Robichon A, Burgess E, Butland S, Shaw RA, Coulthard A, Pererira HS, Greenspan RJ, Sokolowski MB. 1997. Natural behavior polymorphism due to a cGMP-dependent protein kinase of Drosophila. Science 277: 834-836.

Purves D, Lichtman JW. 1985. Principles of neural development. Sinauer, Sunderland, MA.

Renn SC, Park JH, Rosbash M, Hall JC, Taghert PH. 1999. A pdf neuropeptide gene mutation and ablation of pdf neurons each cause severe abnormalities of behavioral circadian rhythms in Drosophila. Cell 99: 791-802.

Richmond JE, Broadie KS. 2002. The synaptic vesicle cycle: Exocytosis and endocytosis in Drosophila and C. elegans. Curr Opin Neurobiol 12: 499-507.

Ricker JP, Hirsch J. 1985. Evolution of an instinct under long-term divergent selection for geotaxis in domesticated populations of Drosophila melanogaster. J Comp Psychol 99: 380-390.

Ricker JP, Hirsch J. 1988. Genetic changes occurring over 500 generations in lines of Drosophila melanogaster selected divergently for geotaxis. Behav Genet 18: 13-25.

Robertson A, ed. 1980. Selection experiments in laboratory and domestic animals. Commonwealth Agricultural Bureau, Slough, United Kingdom.

Roguev A, Bandyopadhyay S, Zofall M, Zhang K, Fischer T, Collins SR, Qu H, Shales M, Park HO, Hayles J, et al. 2008. Conservation and rewiring of functional modules revealed by an epistasis map in fission yeast. Science 322: 405-410.

Simon MA, Botwell DL, Dodson GS, Laverty TR, Rubin GM. 1991. Ras1 and a putative guanine nucleotide exchange factor perform crucial steps in signalling by the sevenless protein tyrosine kinase. Cell 67: 701-716.

Sokolowski MB. 1980. Foraging strategies of Drosophila melanogaster: A chromosomal analysis. Behav Genet 10: 291-302.

Stent G. 1981. Strength and weakness of the genetic approach to the development of the nervous system. Annu Rev Neurosci 4: 163-194.

Toma DP, White KP, Hirsch J, Greenspan RJ. 2002. Identification of genes involved in Drosophila melanogaster geotaxis, a complex behavioral trait. Nat Genet 31: 349-353.

Tong AH, Lesage G, Bader GD, Ding H, Xu H, Xin X, Young J, Berriz GF, Brost RL, Chang M, et al. 2004. Global mapping of the yeast genetic interaction network. Science 303: 808-813.

Tully T, Hirsch J. 1982. Behavior-genetic analysis of Phormia regina. I. Isolation of pure-breeding lines for high and low levels of the central excitatory state (CES) from an unselected population. Behav Genet 12: 395-415.

Vargo M, Hirsch J. 1986. Biometrical and chromosome analyses of lines of Drosophila melanogaster selected for central excitation. Heredity 56: 19-24.

Wade MJ, Goodnight CJ. 1998. Perspective: The theories of Fisher and Wright in the context of metapopulations: When nature does many small experiments. Evolution 52: 1537-1553.

Weber KE. 1990. Selection on wing allometry in Drosophila melanogaster. Genetics 126: 975-989.

Weber K. 1996. Large genetic change at small fitness cost in large populations of Drosophila melanogaster selected for wind tunnel flight: Rethinking fitness surfaces. Genetics 144: 205-213.

Weber K, Eisman R, Morey L, Patty A, Sparks J, Tausek M, Zeng ZB. 1999. An analysis of polygenes affecting wing shape on chromosome 3 in Drosophila melanogaster. Genetics 153: 773 786

Weber K, Eisman R, Higgins S, Morey L, Patty A, Tausek M, Zeng ZB. 2001. An analysis of polygenes affecting wing shape on chromosome 2 in Drosophila melanogaster. Genetics 159: $1045-1057$.

Weber K, Johnson N, Champlin D, Patty A. 2005. Many P-element insertions affect wing shape in Drosophila melanogaster. Genetics 169: 1461-1475.

Weber KE, Greenspan RJ, Chicoine DR, Fiorentino K, Thomas MH, Knight TL. 2008. Microarray analysis of replicate populations selected against a wing-shape correlation in Drosophila melanogaster. Genetics 178: 1093-1108.

Wilson RJ, Goodman JL, Strelets VB, FlyBase Consortium. 2008. FlyBase: Integration and improvements to query tools. Nucleic Acids Res 36: D588-D593.

Wright S. 1931. Evolution in Mendelian populations. Genetics 16: 97-159.

Wright S. 1963. Genic interaction. In Methods in mammalian genetics (ed. WJ Burdette), pp. 159-192. Holden-Day, San Francisco.

Wright S. 1968. Evolution and the genetics of populations, Vol. 1. University of Chicago Press, Chicago, IL.

Wright S. 1982. Character change, speciation, and the higher taxa. Evolution 36: 427-443.

Yamamoto A, Zwarts L, Callaerts P, Norga K, Mackay TFC, Anholt RRH. 2008. Neurogenetic networks for startle-induced locomotion in Drosophila melanogaster. Proc Natl Acad Sci 105: 12393-12398. 


\section{$\$_{\mathrm{CSH}}^{\infty}$ Cold Spring Harbor Symposia SYMPOSIA on Quantitative Biology}

\section{Selection, Gene Interaction, and Flexible Gene Networks}

\section{R.J. Greenspan}

Cold Spring Harb Symp Quant Biol 2009 74: 131-138 originally published online November 10, 2009 Access the most recent version at doi:10.1101/sqb.2009.74.029

References This article cites 68 articles, 12 of which can be accessed free at: http://symposium.cshlp.org/content/74/131.full.html\#ref-list-1

License

Email Alerting Receive free email alerts when new articles cite this article - sign up in the box at the Service top right corner of the article or click here.

To subscribe to Cold Spring Harbor Symposia on Quantitative Biology go to: http://symposium.cshlp.org/subscriptions 